Lo Bianco, Joseph (2008). Educational Linguistics and Education Systems. In B. Spolsky \& F. M. Hult (Eds) The Handbook of Educational Linguistics (pp. 113-127). Maldon, MA: Blackwell

Publishing. http://au.wiley.com/WileyCDA/WileyTitle/productCd-1405154101.html

(C) 2008 by Blackwell Publishing Ltd

\title{
Educational Linguistics and Education Systems
}

\section{Joseph Lo Bianco}

\section{Foundations}

Education systems are principally the property of states. Even if authority is devolved to semiautonomous bodies such as religious, ideological, regional-ethnic, or other parent-controlled agencies for the delivery of schooling, or higher or specialized education, states typically licence, authorize, fund, or certify educational practices. Therefore in a diverse range of ways all education systems carry the imprimatur and conditioning of political systems. State interest in educational practice is therefore governed either by overt control, by investment, or by toleration conditions. The overarching interest of states for what happens in formal systems of education is therefore deep and longstanding.

To speak comprehensively of the language activities potentially undertaken within such education systems, however they are governed, needs to transcend the mediation of the various delivery agencies. Although such agencies can condition the specific lingual characteristics of formal education, a broad depiction of the proto-typical linguistic education of young people can still be discerned. The following eight points constitute therefore state sanctioned secondary linguistic socialization:

1 extending the dialect repertoire of "majority" children's domestic language competence to include standard language literate capability (minimally reading and writing, but for elites this often involves critical and imaginative literacy as well);

2 extending the non-standard language competence of socially, regionally, and other minoritized communities to include mastery of spoken and written standard language norms;

3 inculcating mastery of the elevated linguistic registers and styles validated by national value systems and appropriate to context-reduced academic activity;

4 teaching the national standard language to non-speakers whether they are of immigrant or indigenous origin;

5 specialization of formal standard literate knowledge around the disciplinary conventions of particular fields of application, such as professions, institutions, or occupations;

6 providing standard language and literacy provision for deaf, blind and other children with language-connected special needs;

7 occasional concessions to the language backgrounds of learners, be these non-standard varieties of the national language, or languages other than the national language whether of immigrant or indigenous origin; and, finally

8 teaching prestige, strategic, or status languages.

This secondary lingual socialization differs from primary linguistic socialization (Watson-Gegeo, 2004) in its greater degree of formality, its link to certification, its systemic moderation and its material and symbolic consequences.

Religious, ideological, regional-ethnic, or other parent-controlled agencies make use of various degrees of autonomy from state direction to shape curricula, and in so doing vary and modulate this secondary linguistic socialization in particular ways. 
In the context of this lingual profile which education systems aspire to produce educational linguistics, at least in its early conceptions (Spolsky, 1978), means something like the application of explicit linguistic knowledge to problems of teaching and learning. Its fundamental questions are: How can language be characterized, constrained, and defined in general terms? How can language learning be sequenced for teaching? How does learner processing of linguistic input influence teaching and curriculum design? How can language learning, both holistically and in its various component parts, be assessed? How does academic and context-reduced language, especially literacy and literate practice, relate to spoken language? and, crucially, How can reading and writing be sequenced, constrained and taught?

Early views of what constitutes explicit linguistic knowledge came directly from the situationindependent insights and understandings generated by the main branches of linguistic scholarship with its classical divisions of phonology, morphology, and semantics. This science of verbal communication was conceived as producing knowledge portable across context, a kind of calculus in which universally relevant knowledge was applied to the practice of language use and teaching in education systems. Education systems are ultimately formalized institutions for knowledge creation, transfer, and certification and because explicit linguistic knowledge was understood as essentially mentalist it was seen as universally applicable.

Combined, then, educational linguistics and education systems refer to the multiple ways in which formal processes of organizing the transmission of content knowledge, including knowledge of and about language, is shaped by meta-linguistic knowledge produced by a science of linguistics. In recent decades this foundational assumption has ceded space dramatically to more situationalist and constructivist paradigms in both fields, both the language sciences and the sciences of learning have made social criteria, situation, context variability, and co-construction central tenets of their disciplines.

This change can be demonstrated in a contemporary way by reference to the 'future-person' ideology, a composite person imagined in the many policy documents issued by the supra-national agencies of Europe. In this large body of policy literature ${ }^{1}$ is depicted the lingual capabilities of the projected and imagined future citizen of Europe, a mobile, polyglot, multicultural, literate, broad-minded, and conscientious transnational. The following is an abstraction of this idealized subject explicated from the voluminous but usually unintegrated directives, declarations, statements, pronouncements, and other desiderata issued by the agencies of the European Commission and the Council of Europe in recent decades.

The communicative capabilities and profile of this polylingual polymath can be synthesized as follows. First, homo europaeus would speak a primary language of identity, rooted in place and local belonging, nurtured by claims to authentic representation of Europe's primordial regions: sometimes called an autocthonous language, in New World settings called an indigenous language, or what Dante Alighieri (Lo Bianco, 2005a) called locutio prima. The circumscribed identity of this language is extended by mastery of a national language, what for Dante was locutio secondaria, and what in Europe is constituted by the formative importance of language defined statehood (Seton-Watson, 1977). In much of the discourse that underlies European official pronouncements the languages of place invoke essential personhood, primary identity, while the language of the nation transcends locality and invokes wider political citizenship. This bilingualism of place and nation is further supplemented by a wider and emergent compact of citizenship that is trans-European, so our ideal citizen would command a language that transcends his or her particular identity, and particular nationality; although technically a foreign language, it would be marked as a language of wider European communication and there also invoking identification and place. The realities of interconnection of global markets whose access is facilitated most easily by English also requires widespread, near-universal, mastery of English (and, realistically, Englishes). In the essentially 
economic and political discourses of the supra-national institutions of Europe these language competencies - local identity language, national language, language of Europe-wide communication and then global English - might also extend to include multiple, partial and temporary language skills a citizen could require during various stages of his or her professional life. All of these, of course, are intimately and ultimately associated with European literacies, possibly with different orthographic scripts, but certainly with internal language literacies such as prose writing, information or document literacy, and quantitative or numerical literacy (OECD, 1996a, b) and all of these in turn mediated by the particular literacy requirements of information and communications technologies.

This state imagined poly-lingualism needs to be nuanced to accommodate religious, regional, and citizenship diversity, so that devotional languages, ancestral languages new to Europe, and forms of speech other than spoken ones all extend the imagined communicative profile of the future European. A central tenet of emergent Europe is the notion of mobile trans-nationality. This forging of a common European geopolitical future consciousness is forward-looking but must make amends for the past. This is why the new inclusiveness promulgated in many documents issued by the supra-national agencies of Europe contains amelioration for sub-national grievances, oppression, and alienation. Hence minorities, especially the marginalized and socially excluded, are largely defined in these statuses by the homogenizing tendencies and overwhelming power of nationality-based statehood with its past practices of neglect, assimilation, and even obliteration of differences (Gellner, 1983; Greenfeld, 1992; Hobsbawm, 1992; Smith, 1995; Hroch, 1996; Ager, 1996).

Within the foundations of educational linguistics therefore we find resonances of all these phases of how language has marked in the past and continues today to mark aspirations and history. The lingual expectations of education systems are wide ranging because they aim to produce many tools: for competing in cut-throat labor markets in a globalizing economy, for meeting the persistent demands of identity, for the refusal of national states to concede to globalization, for religious affiliation and devotion, and for marking the survival and vitality of sub-national identities; all differences marked and made possible with and through language.

\section{Core Themes}

The foundations of educational linguistics, though these are rarely elucidated, are fashioned by the interaction between languages sciences that have shifted from a universalist paradigm to a more socially situated one. In turn educational linguistics orients teachers, learners, and curriculum designers to systemic purposes inherent in compulsory education. Within compulsory education, both schooling and post-initial education, we find the historical inheritances suggested above. Curriculum can be seen as the planned learning experiences that formal institutions provide to learners, suggesting both different theories of knowledge as well as different purposes for knowing. Typically, or classically, curricula reflect orientations to knowledge, or ways that curriculum carries the primary missions, or social purposes, that underlie educational delivery. Four such frames of reasoning are proposed below to capture these overall philosophies of educating institutions. As each is described the educational linguistics they contain are discussed, drawing on the eight secondary linguistic socialization fields identified above. While educational linguistics contributes distinctive disciplinary focus, concepts, methods, and history, it also takes distinctive form in each of the following types of curriculum, which, of course, are idealizations while in practice there are many hybrid forms.

The four curriculum types are:

1 skills: how skills are transmitted and applied in economically oriented education;

2 humanist intellectualism: how eloquence and expression invoke elevated culture;

3 transcendence: how political ideology and religious devotion are cultivated; and

4 nationing: how loyal citizenship to nationality-defined states is inculcated. 


\section{Skills: An economistic-vocationally oriented curriculum}

Some curricula are organized around an overarching rationale which involves the intersection of education with the skill requirements of the labor market. Curricula which aim to prepare learners for some kind of successful integration within the labor market can be either narrow or less narrow, occupationally specific or life-skills focused. In these kinds of curricula teaching aims to facilitate the acquisition of skills which are seen to be discrete or separately specifiable, and are taught via pedagogies that stress explicit teaching, identifying subskills and teaching these separately and aiming through apprenticeship to combine the subskills.

Attitudinal ideals are also invoked, usually via the development of personal qualities relevant for a working subject (diligence, professional ethics, norms and standards) to satisfy extrinsic occupationally motivated orientations or the requirements of professional certification.

Educational linguistics fashioned for the labor market focuses on the generic structures of language, the text types that typically occur, are valued, and practiced in the fields of endeavor where the skills are applied. An example of educational linguistics for skills transmission from foreign language teaching is described by Staddon (1996). In this instance the Faculties of Engineering and Arts at Monash University in Australia introduced a combined degree in Arts and Engineering. Requiring both linguistic and technical expertise of students and teachers, this kind of language for specific purposes imposed the need for interdisciplinary collaboration between linguists (French speakers) and civil engineers (English speakers). This interaction between language experts and engineering experts produced an amalgam of applied expert linguistic knowledge and the disciplinary knowledge of engineering. This intersection is precisely the domain of educational linguistics. The educational linguistics was expressed in the modes for delivering students' professional preparation through the acquisition of skills and knowledge required to use French, pragmatically and effectively, in the engineering workplace and in related social situations, showing an understanding of French engineering practices, or rather French in engineering practices. The specificity of communication practices, discourses, technical vocabulary, terms of art, and the generic organization of writing and information presentation for engineering purposes, using shared knowledge of the discourse community of engineers, etc., constitute some of this educational linguistics. Pedagogically programs of language for specific purposes work with realistic and task-based learning activities selected for their typicality, and real-world authenticity, as site-based instantiations of general principles of communication. Oral and written inter-relations are also involved since translating technical documents into oral instructions is an expected part of competently functioning as a qualified engineer working in French.

The skills curriculum has a national analogue. On a more wide-ranging basis we can identify characteristics of a systemically skills-oriented approach in the public education system as a whole. Better known perhaps as human capital based curriculum, Singapore's linguistic practices in its education systems are motivated by "linguistic instrumentalism" (Wee, 2004) or "linguistic capital" (Silver, 2005). Analyzing the essential reasoning that underlies language education planning in the city state, these writers show how the underlying rationales, similar to what Ruiz (1984) called "policy orientations," make language education choices and adopt methodologies oriented to achieving skills outcomes, human capital, labor market applicable outcomes premised on an underlying economic rationality. Unlike Engineering French, whose more socially limited purpose is to advance domainspecific French language proficiency of engineers though an essentially English-speaking education system, the Singapore example epitomizes an entire national educational linguistics, motivated by calculations of the material outcomes of educational linguistics. It would be wrong to imagine goals of social harmony and inter-ethnic harmony are neglected in such an approach, even these are linked closely to the underlying human capital ideology; the policy settings clearly relate economic success to inter-ethnic harmony through more widely distributing social opportunity and rewards. 
The educational linguistics involved ranges from choices about language of instruction through to classroom-based documentation of elementary school literacy practices and pedagogy for learners whose home language traditions involve different orthographies. Singapore's educational linguistics is one of the most explicit in the world, largely because of this level of institutionalized diversity, and gives effect to an English-knowing bilingualism (Pakir, 2003) in the service of a project of national unity based on economic instrumentalism. Although the wider discourses of linguistic instrumentalism and language capital prevail, these are combined with claims for a continuation of language-based ethnic identities. While there can be tension between non-English based ethnic identities with English based economic advantage (Lo Bianco, 2007), and while it is apparent that the non-English languages stand in diglossic inferior domain status to English, the policy has achieved extraordinary success as applied educational linguistics.

The formula of identity and advantage allocated differentially between languages is well expressed in the following statement from Mr Tharman Shanmugaratnam, appropriately the Senior Minister of State for Trade and Industry for Singapore, who during an awarding on October 13, 2002 of Most Inspiring Tamil Teacher stated that studying the "Mother Tongue":

helps our students to imbibe values and to appreciate the accumulated knowledge and wisdom contained in our cultural heritage. As bilingual learners, children are provided with more than one set of lens, enabling them to perceive the world and encoding their experiences in different ways. It allows them to reach a deeper understanding of their own identity, and a sense of belonging to community and country.... Our bilingual policy in education remains a key social and economic imperative for Singapore, as relevant now as it has been in the last few decades. Proficiency in the English language has given Singaporeans a key advantage in a globalised economy. It gives us relevance to global companies and keeps us at the intersections of global trade and investment. It creates good jobs for Singaporeans, now and in the future. (Shanmugaratnam, 2002: 1)

\section{Eloquence: A humanistic-intellectual paradigm}

When curricula are conceptualized as in some sense 'humanizing', the educational linguistics which results makes use of notions of eloquence, expression, rhetoric, and elevated culture. These overarching purposes speak of a connection between 'knowledge' and 'civilization'. Informing learners of time-validated canonical thought, works of art, and literature (bodies of knowledge which are elevating in cultural and even spiritual modes) distinguishes this class of curricula. The frequently encountered 'mission' of school and university curricula built from this paradigm involves claims to personal transformation and growth for individuals and sometimes for whole societies.

The educational linguistics that is deployed in curricula such as these is principally about rhetoric and historical linguistics, change in language over time, nuance in expression and verbal repertoires as expressive of either emotional, psychological, or national and cultural states.

The kinds of pedagogies adopted in curricula with overt aims of nurturing intellectualism, or advancing abstractions like 'civilization', quite often favor only the study of literary texts removed from ordinary people, their discourse, and experiences. Murphy's (1988) characterization identifies four stages of including broad cultural aims in foreign language teaching, each shaped by an educational linguistics that prevailed.

The civilization approach is the first, which assumes that a separately specified curriculum exists for culture which is taught after the language has been learned. The impact of applied linguistic research, or educational linguistics of different phases, then shapes the following three: Audio-lingualism assumes that there is no specific cultural aspect to language pedagogy, and instead aims to produce 
grammatical correctness, seeing culture as a disconnected field. Educational linguistics then leads to the promulgation of an array of teaching methods collectively called communicative, which take for granted that culture can influence communication and teach culture explicitly when it is needed to enhance communication. This is a notion of culture as non-linguistic elements required for communication. Finally, in intercultural pedagogies Murphy argues that language has come to be seen as itself a cultural practice. This assumption of inseparability of language and culture requires research between the learner's language and the target language to identify culturally infused forms and instances of language use which can then be taught directly.

The contemporary context of cultural fusion and hybridity attenuates even this sense of bounded cultures and languages, tied to single foreign countries and speaker populations. Trans-national and more critical approaches to culture itself problematize the assumptions and the practices of educational paradigms of language that appear to reinforce outmoded views of communication, cultural value, and judgmental positions about eloquence tied to the particular forms of speech of some groups. Educational linguistics here can be seen to have revolutionized pedagogical practices, based principally on the insights of variationist sociolinguistics, classically deriving from the work of dialectology (Labov, 1972; Baugh, 2000) whose systematic way to show rule-governed predictability, logic, and order in stigmatized speech forms has directly shaped education systems. Indeed in the United States a long tradition of litigation around teacher and system attitudes to non-standard speech forms has shown the power of educational linguistics, though also its controversies and failures (Krashen, 1996; Crawford, 2002).

\section{Virtue: Paradigms of religion or social ideology}

Some curricula aim to reproduce norms of life that derive from ethnicity, religious creed, or moral ideology. These politico-ideological and religious ideals are usually encapsulated in virtue, a moral paradigm rooted in the association of knowledge with ethical action. Although curricula which invoke these ideals also draw on vocational or humanistic-intellectual paradigms for organizing learning experiences, these are usually interpreted only within the ideological and systemic parameters of the 'sectional' character of the curriculum. Educational linguistics which serves educational systems premised on transcendent notions of the purposes of learning shares with all other educational linguistics the idea of making general instruction more effective, but also serves unique goals of teaching, content sequencing, assessment, and evaluation associated with modes of practice particular to the ideology of the schools involved.

A moral-religious or non-religious ethical or sectional curriculum ideal typically locates the value of knowledge (not only the selections of knowledge but how knowledge and skill are construed as 'valuable' or less so) within preexisting, or given, orders and patterns of social, ideological, or moral systems. These systems pre-date the learner, are sanctioned by systems of judgment that prevail beyond contest, and are presented as ideal behavior and identity models into which learners are to be inducted.

Although the primary purposes of these approaches to learning are reproductive, or preservationist, educational linguistics applied in these contexts is not denied its exploratory character, nor that of research and discovery. However, the political and religious values and ideals encountered in such curricula can find their way into how knowledge about applied language studies is framed, collected and valued. Reproducing patterns of life, devotional practices, particular valued languages, or reading practices that have time-honored value among new generations is the overriding goal of such curricula. Aiming therefore to reproduce intergenerationally patterns of life, ethnic identification, or religious devotion lends educational linguistics a particular functionality and occasionally a sense of urgency. 
Social transformation as a curriculum paradigm can aim for one of three kinds of change. First that talented individuals have constraining circumstances removed and are enabled to acquire cultural capital for personal/individual advancement. Second, that the characteristics of the group which constitute its disadvantage are contested so that not only isolated individuals but the group as a whole is assisted; this change being the ideal that underlies the curriculum ethos. Third, and more ambitious still, that the social context is itself transformed so that it becomes defined by diversity and removes any privilege that attaches to selected groups. These more ideological parameters of curriculum ethos have a long tradition not in formal educational linguistics, but in critical studies, in the work that derives from Marxist, neo-Marxist, and Freirian (Spring, 1998) influenced views of literacy. This kind of educational linguistics today draws on critical reasoning and makes use of the ideas of sociologists, such as Bourdieu (1991), whose identification of the ways in which material advantage accrues to symbolic power, and specifically to the command of powerful registers of communicative skill, links directly educational linguistics and education systems as producers and re-producers of advantage.

\section{Nationing: The discourse of loyal citizenship to nationality-defined states}

The greatest weakening of the educational systems' classic function of inculcating identity loyalties has been the economic vocationalism of trans-national capital. Despite this, nationing, both in new nations intent on forging identities larger than regional or local ones, and in established nations intent on preserving distinctiveness, utilizes linguistic based narration, story telling about national cohesion and unity, or subliminal and continual reminders of the persistence of nationality (Billig, 1995).

In the passage from pre-national to national forms of sociality schools were transformed from their various individualistic functions and combined into education systems, under self-conscious politics interested in making nations and achieving national unity via education systems which provided the systematic, and therefore repeatable, socialization that families could not. Industrialism intensified the need for standardization of expressive culture, but added the requirement for standardized mass literacy and so nationing, and economic need, established the basic character of today's educational practice. As early as 1791 the French nobleman and diplomat Talleyrand pronounced before the French Convention that aimed to invent a new polity to displace tradition with modernity the essential role for education: "Elementary education will put an end to this strange inequality. In school all will be taught in the language of the Constitution and the Law and this mass of corrupt dialects, these last vestiges of feudalism will be forced to disappear" (cited in Wright, 2004: 62).

For Brunot (1927), the great documenter of French linguistic consolidation, the critical moment was the state deciding that families would no longer have exclusive rights over the lingual ways of their children. The young, like the new, are a challenge to society, any society, and all societies work out ways to make the future resemble the past. Because a society must always renew itself, this renewal has a dual character: horizontal and vertical.

Horizontal cultural reproduction involves bringing in the different from outside the society and assimilating them. Vertical cultural reproduction involves bringing up the young from inside the society and socializing them. The French state decided that the school should replace the family and set up the secondary socialization of schooling: home was for learning to walk and tie shoe laces, primary socialization, but the school became the nationing instrument. When schools were individual institutions the socialization they practiced modeled the values and behaviors of their individual founders. However, self-conscious polities interested in forging bonds of national community, require more systematic action. Aiming to achieve unity via formal education Talleyrand and the French Convention organized schools into education systems to facilitate systematic and repeatable socialization.

The original target was the standard literate form of French, the language of state and law, which was 
spreading internationally but was unknown to many French, in villages and remote regions (Talleyrand's "strange inequality"). This disparity was perceived as a problem of families, of enduring local loyalties and of fragmented schooling, and was dealt with by instituting a formal education system tied to the explicit project of ideological language nationalism.

\section{Research Practice}

Research and practice in educational linguistics and in education systems is undergoing three major transformations. First, the researched languages from which generalizations about learning and teaching are drawn are diversifying rapidly away from dominantly Western ones. Second, what counts as literacy, and the media through which educational practice is exchanged, is being transformed dramatically by information and communications technologies. Third, education systems themselves are undergoing rapid change. Learners learn a great deal about all fields of knowledge, including language, from horizontal connections they make with age peers, unmediated by adults, whether the primary socializers of the home or the secondary socializers of the school.

Much of the literature on educational linguistics derives from First World settings, or from post-colonial national language educational planning, or at least from relatively settled relations between what counts as spoken and what counts as written language. While too many predictions of change brought about by information and communications technologies prove to be unwarranted, it is clear that the rapid advances in electronic and digital communication are changing conventions of writing. (Chat groups, for instance, disrupt traditional assumptions of temporal displacement that we have long seen as inevitable in written communication. Chat groups and other forms of digital writing which are instantaneously "consumed" resemble the more iterative and negotiated practices of spoken language.)

Many of the settings in which ideas about language have been researched are shaped by Western, or Westernized, literacy practices and the contrastive linguistic examinations that have fashioned the field have looked at binaries, learner language and target language, that are either within the Western paradigm, or that involve at least one Western language, most often English. Literacy research is often characterized by expectations of shared alphabetic roman orthographies. Looking at the titles of journals in contemporary educational linguistics shows a major diversification of sources, settings, and relationships in response to the greater diversification of societies. Research and practice in educational linguistics will also of course need to deal much more systematically with the deep and pervasive transformation of English, for which claims of its emergence as a "post-identity language" (Lo Bianco, 2005b), and its growth as "basic skill" (Graddol, 2006) indicate that relations of identity, linguistic norms, and the consequences for speakers of other languages and whole disciplines of knowledge will accelerate and diversify. And yet, perhaps the most compelling point to be made about research and practice is not that things will change, but that practice is so resistant to research. As Baynham (2003) has pointed out, researchers in adult literacy, bilingual education, and other fields of educational linguistics examine a much richer array of problems and possibilities than relatively conservative institutions of education admit and acknowledge. This research-practice gap is neither particular to educational linguistics, nor particularly unusual, and in some ways is positive. It is reflected in the wide array of curriculum ideologies discussed above, where despite what the science of educational linguistics might propound at any one time education systems draw on bodies of informing ideas, ideologies, and contesting knowledge so that the relation of educational linguistics and language education is never straightforward or unmediated.

In any case, more documentation across radically different sociolinguistic settings will impact on educational linguistics. One of its key assumptions has been that progressive kinds of educational practice emerge from the more descriptive traditions of linguistics encountered in Western academic 
institutions. That Asian educational practices, generally conceived as more conservative pedagogically, perform particularly well in international standardized assessments of learning is already having a washback effect onto curriculum design and educational practice within some Western societies. More documentation of multiple orthographic systems is also emerging, so that the reading and general intellectual consequences of literacy gained in different writing systems and their interaction is beginning to be felt. Hornberger's continua of biliteracy (2003: 315-339) aims to represent the wider range of language ecologies that are being researched at present and suggest that the taxonomies with which educational linguistics has operated will be called to account for more diverse settings.

Among the greatest challenges for educational linguistics will be how to accommodate cognitive attainments given the great diversity of learner backgrounds, sociological circumstances, program delivery modes, and values-centered curricula. Studies responding to this growing complexity should be collaborative endeavors undertaken between scholars trained in applied linguistics and pedagogy with colleagues who focus on sociopolitical ideology, values, and culture.

\section{NOTE}

1 European Commission (2001), Eurobarometer Report 54, Europeans and Languages, February 15, Brussels: European Commission; European Language Council (2001), Universities and Language Policy in Europe, June, Berlin: http://www.fu-berlin.de/elc; Council of the European Union (1995), Linguistic Diversity and Multilingualism in the European Union, Council conclusions, 1853rd Council meeting, General Affairs B, Luxembourg, 12 June; Council of the European Union (1992), Charter of Regional or Minority Languages, Strasbourg: Council of the European Union; Council of the European Union, Framework Convention on National Minorities (1995), Strasbourg: Council of the European Union; Council of the European Communities on the Schooling of Migrant Workers (1977), Directive 77.486; Council of Europe (2001), Common European Framework of Reference for Languages, Learning, Teaching and Assessment, Cambridge: Cambridge University Press; European Commission (1995), White Paper on Education and Training - Teaching and Learning: Towards the Learning Society, Brussels: European Commission.

\section{REFERENCES}

Ager, D. (1996). Language Policy in Britain and France. London/New York: Cassell.

Baugh, J. (2000). Beyond Ebonics: Linguistic Pride and Racial Prejudice. New York/Oxford: Oxford University Press.

Baynham, M. (2003). Adult literacy. In J. Bourne \& E. Reid (eds.), Language Education: World Yearbook of Education 2003 (pp. 109-127). London: Kogan Page.

Bourdieu, P. (1991). Language and Symbolic Power, trans. G. Raymond \& M. Adamson. Cambridge, UK: Polity Press.

Billig, M. (1995). Banal Nationalism. London: Sage.

Brunot, F. (1927). Histoire de la langue française des origins à 1900 [History of the French language from its origins to 1900), vol. 9, part 1. Paris: Armand Colin, 3-14.

Crawford, J. (2002). At War with Diversity: US Language Policy in an Age of Anxiety. Clevedon, UK: Multilingual Matters.

Gellner, E. (1983). Nations and Nationalism. Oxford, Blackwell Publishers.

Graddol, D. (2006). English Next. London: British Council.

Greenfeld, L. (1992). Nationalism: Five Roads to Modernity. Cambridge, MA: Harvard University Press.

Hobsbawm, E. J. (1992). Nations and Nationalism Since 1780: Programme, Myth, Reality (2nd 
revised edn.). Cambridge: Canto.

Hornberger, N. H. (2003). Continua of Bi-Literacy: An Ecological Framework for Educational Policy, Research, and Practice in Multilingual Settings. Clevedon, UK: Multilingual Matters.

Hroch, M. (1996). From national movement to the fully-formed nation: The nation- building process in Europe. In G. Balakrishnan (ed.), Mapping the Nation (pp. 78- 97). New York/London: Verso.

Krashen, S. (1996). Under Attack: The Case against Bilingual Education. Culver City, CA: Language Education Associates.

Labov, W. (1972). Sociolinguistic Patterns. Philadelphia: University of Pennsylvania Press.

Lo Bianco, J. (2005a). Globalisation and national communities of communication. Language Problems and Language Planning, 29(2), 109-133.

Lo Bianco, J. (2005b). No longer a (foreign) language: The rhetoric of English as a post-identity language. The Journal of Chinese Sociolinguistics, 2(5), 17-41.

Lo Bianco, J. (2007). Advantage plus identity: Neat discourse, loose connection: Singapore's Medium of Instruction Policy. In V. Vaish, S. Gopinathan, \& Y. Liu (eds.), Language, Capital, Culture: Critical Studies of Language in Education in Singapore (pp. 5-22). Amsterdam: Sense Publishers.

Murphy, E. (1988). The cultural dimension in foreign language teaching: Four models. Language, Culture and Curriculum, 1(2) 147-163.

OECD (1996a). Literacy, Economy and Society. Paris: Organization for Economic Cooperation and Development.

OECD (1996b). Lifelong Learning for All. Paris: Organization for Economic Cooperation and Development.

Pakir, A. (2003). Singapore. In J. Bourne \& E. Reid (eds.), Language Education, World Yearbook of Education 2003 (pp. 267-280). London: Kogan Page.

Ruiz, R. (1984). Orientations in language planning. Journal of the National Association for Bilingual Education, 8, 15-34.

Shanmugaratnam, T. (2002). Speech by Senior Minister of State for Trade and Industry and Education, at the Tamil Murasu, Most Inspiring Tamil Teacher Award. October 13, http://www.moe.gov.sg/speeches/2002/sp14102002.htm

Silver, R. E. (2005). The discourse of linguistic capital: Language and economic policy planning in Singapore. Language Policy, 4(1), 47-66.

Smith, A. D. (1995). Nations and Nationalism in a Global Era. Cambridge: Polity Press.

Spolsky, B. (1978). Educational Linguistics: An Introduction. Rowley, MA: Newbury House.

Spring, J. (1998). Education and the Rise of the Global Economy. Mahwah, NJ: Lawrence Erlbaum.

Seton-Watson, H. (1977). Nations and States. London: Methuen.

Staddon, S. (1996). Engineering French: The origins, development of a French for Special Purposes subject. In J. Burston, M, Monville-Burston. \& J. Warren (eds.), Issues and Innovations in the Teaching of French, ALAA Occasional Paper 15, 125-140.

Watson-Gegeo, K. A. (2004). Mind, language, and epistemology: Toward a language socialization paradigm for SLA. The Modern Language Journal, 88(3), 331-350.

Wee, L (2004). Linguistic instrumentalism in Singapore. Journal of Multilingual and Multicultural Development, 24(3) 211-223.

Wright, S. (2004). Language Policy and Language Planning: From Nationalism to Globalisation. Basingstoke, UK: Palgrave. 


\section{University Library}

\section{- M M I N E R VA A gateway to Melbourne's research publications}

Minerva Access is the Institutional Repository of The University of Melbourne

Author/s:

Lo Bianco, J

Title:

Educational Linguistics and Education Systems

Date:

2008-03-10

Citation:

Lo Bianco, J. (2008). Educational Linguistics and Education Systems. Spolsky, B (Ed.). Hult, F (Ed.). The Handbook of Educational Linguistics, (1), pp.113-126. Blackwell Publishing Ltd.

Persistent Link:

http://hdl.handle.net/11343/112282 